DOI: https://doi.org/10.24127/ajpm.v9i3.2889

\title{
DESAIN PENGEMBANGAN MODUL MATEMATIKA BERBASIS SANTUN BERBAHASA UNTUK SISWA SLOW LEARNER DI SEKOLAH DASAR
}

\author{
Savitri Wanabuliandari ${ }^{*}$, Ristiyani ${ }^{2}$, Nuning Kurniasih ${ }^{3}$ \\ ${ }^{1 *, 2}$ Universitas Muria Kudus, Kudus, Indonesia \\ ${ }^{3}$ Universitas Padjajaran, Bandung, Indonesia \\ *Corresponding author. Kayuapu Kulon, Gondangmanis, Kec. Bae, Kabupaten Kudus, Jawa Tengah 59327 \\ E-mail: $\quad$ savitri.wanabuliandari@umk.ac.id $^{1 * 1}$ \\ ristiyani@umk.ac.id $^{2)}$ \\ nuning.kurniasih@unpad.ac.id $^{3)}$
}

Received 26 June 2020; Received in revised form 10 September 2020; Accepted 25 September 2020

\begin{abstract}
Abstrak
Tujuan dari penelitian ini adalah (1) menganalisis hasil studi lapangan terkait kebutuhan desain modul matematika berbasis santun berbahasa untuk siswa slow learner, (2) menganalisis hasil temuan di lapangan dan hasil FGD terkait kebutuhan desain modul matematika berbasis santun berbahasa untuk siswa slow learner, (3) merumuskan desain draf modul matematika berbasis santun berbahasa untuk siswa slow learner. Metode penelitian yang digunakan adalah deskriptif. Metode deskriptif ini digunakan untuk menggambarkan desain pembuatan modul matematika berbasis santun berbahasa. Modul ini dirancang dengan memperhatikan karakteristik siswa slow learner di sekolah dasar. Hasil penelitian menunjukkan bahwa (1) berdasarkan hasil studi lapangan modul matematika berbasis santun berbahasa membahas materi pembelajaran matematika secara koheren dan jelas perlu untuk dikembangkan dengan memperhatikan kesantunan dalam setiap kalimat baik kalimat perintah, penjelasan dan pertanyaan; (2) berdasarkan temuan dan FGD perlu dirancang modul yang menggunakan kurikulum 2013, ada kegiatan proyek yang menarik, memasukkan bahasa yang santun, isinya runtut dan detail, tema tentang kebudayaan, memperhatikan karakter siswa slow learner, desain halaman dan sambul berkaitan dengan budaya; dan (3) Desain draft modul matematika berbasis santun berbahasa menyediakan 3 bagian dasar dari pengantar, konten, dan penutup, serta desain setiap kegiatan pembelajaran disusun menggunakan akronim yang unik sehingga menarik dan mudah diakses oleh siswa yang lambat.
\end{abstract}

Kata kunci: Modul matematika; santun berbahasa, slow learner.

\begin{abstract}
The objectives of this study were (1) analyze the results of field studies related to the need for languagebased mathematics module design for slow learner students, (2) analyze the findings in the field and the results of FGDs related to the need for language-based mathematics module design for slow learner, (3) formulating a draft design of a mathematics module based on polite language for slow learner students. The research method is descriptive. It used to describe the design of a mathematics module based on polite language. This module is designed with students in mind. Slow learner in elementary school. The results showed that (1) based on the results of the field study, the language-based mathematics module discusses mathematics learning material in a coherent and clear manner, it needs to be developed by paying attention to the politeness in the sentence of each command sentence, explanation and question; (2) based on the findings and FGD, it is necessary to design modules that use the 2013 curriculum, have interesting project activities, include helpful language, coherent and detailed content, themes about culture, paying attention to the character of students who are slow, page design and chutney related to culture; and (3) The design of the draft mathematics module based on polite language provides 3 basic parts of the introduction, content, cover, and design of each learning activity which is arranged using unique acronyms so that it is attractive and easily accessible to slow students.
\end{abstract}

Keywords: Math modules; polite language; slow learner.

This is an open access article under the Creative Commons Attribution 4.0 International License 
DOI: https://doi.org/10.24127/ajpm.v9i3.2889

\section{PENDAHULUAN}

Di Indonesia bullying terutama di sekolah bukan merupakan hal yang baru. Bullying dapat memberikan dampak secara fisik maupun psikis terhadap korbannya. (Kaltiala \& Riittakerttu, 2011) anak yang mengalami bullying akan memiliki resiko negatif dimasa mendatang, seperti masalah kejiwaan, bunuh diri, sampai pelampiasan pada alkohol dan obat terlarang. (Shetgiri, 2013) akibat negatif dari perilaku bullying ini sendiri bisa berujung pada depresi, merasa rendah diri, dan selalu cemas dalam melakukan segala sesuatu. Berdasarkan laporan dari UNICEF tahun 2016 menyebutkan bahwa Indonesia menempati peringkat pertama untuk kasus bullying pada anak di ASEAN (Waliyanti et al., 2018). Lenny Rosalin (Setyawan, 2017) menjelaskan bahwa $10 \%$ pelaku kekerasan pada anak hingga tahun 2017 adalah guru.

Peran seorang guru tidak hanya sebagai tenaga pendidik. Guru dituntut untuk lebih memahami karakteristik siswanya. Salah satu siswa yang perlu dipahami karakteristiknya adalah siswa Slow learner. Siswa Slow learner ini memiliki kelemahan disalah satu bidang akademik maupun diseluruh bidang akademik. IQ siswa Slow learner berkisar antara 70 sampai 90. Siswa Slow learner ini membutuhkan waktu yang lebih banyak untuk memahami materi. Siswa Slow learner harus berlatih berulang-ulang agar mencapai batas minimal yang ditetapkan. (Borah, 2013) menyebutkan bahwa siswa slow learner bukan siswa cacat tetapi merupakan siswa yang mempunyai kemampuan kognitif di bawah temantemannya. Karena karakteristik inilah siswa slow learner tak jarang mengalami verbal bullying.
Mata pelajaran yang sering terjadi verbal bullying adalah mata pelajaran Matematika. Matematika sendiri selalu dekat dengan kehidupan manusia. Matematika merupakan ilmu yang harus dipelajari karena manfaat dan kegunaannya dalam kehidupan seharihari. (Putri et al., 2013) menyebutkan bahwa matematika memiliki peran penting dalam kehidupan sehari-hari, karena kemampuan matematika dapat digunakan untuk mengatasi persoalan kehidupan. Oleh sebab itu guru hendaknya memahami karakteristik siswanya agar pemahaman terhadap matematika dapat tercapai.

Pemahaman siswa tidak akan tercapai jika tidak diimbangi dengan penggunaan bahasa yang baik. (Wanabuliandari \& Ristiyani, 2019) menyebutkan bahwa dalam pembelajaran seringkali guru menggunakan kalimat negatif. Kalimat negatif ini tentu saja berkaitan dengan psikologi siswa. Kalimat negatif ini juga seringkali dikaitkan dengan verbal bullying. Guru sebenarnya tidak sengaja melakukan verbal bullying terhadap siswa slow learner. Hal ini dikarenakan guru belum memahami tindakkannya tergolong verbal bullying atau tidak. Berdasarkan hasil wawancara dengan guru didapatkan hasil bahwa guru masih menggunakan bahasa yang kurang satun seperti "awas ya kalau tidak bisa menjawab, "yang tidak mengerjakan kerjakan di luar saja", "ayo diam", dll. Bahasa yang kurang santun ini yang merupakan bentuk verbal bullying. Perilaku verbal bullying ini sering dialami oleh siswa slow learner. Karena guru kurang sabar dalam memahami karakteristik siswa slow learner sehingga terjadi verbal bullying. Jika dibiarkan akan mengganggu perkembangan psikologi siswa slow learner. Oleh karena itu, guru perlu 
ditunjang oleh sumber belajar yang dapat memahami karakteristik siswa slow learner.

Berdasarkan hasil studi lapangan terkait sumber belajar yang digunakan oleh guru meliputi buku dari paket dari pemerintah dan LKS dari penerbit. Sedangkan berdasarkan hasil wawancara guru ditemukan bahwa guru belum pernah mengembangkan bahan ajar sendiri. Padahal bahan ajar yang sesuai dengan karakteristik siswa slow learner diperlukan agar proses pembelajaran berjalan dengan baik. Oleh karena itu agar proses pembelajaran berjalan dengan baik guru perlu mengembangkan bahan ajar sendiri.

Salah satu bahan ajar yang dapat dikembangkan oleh guru untuk menunjang pembelajaran dengan siswa slow learner adalah modul. (Syahroni et al., 2016) menyebutkan bahwa modul dapat digunakan untuk komunikasi dua arah. (Sipayung \& Simanjuntak, 2017) yang menyebutkan bahwa modul merupakan bahan ajar yang berisi materi secara sistematis serta menarik yang terdiri dari isi metode dan evaluasi yang dilakukan secara mandiri. (Ekayanti, 2017) menjelaskan bahwa modul merupakan bahan ajar yang dapat dipelajari sendiri dan disesuaikan dengan kecepatan belajar siswa. (Ramadhani \& Amudi, 2020) menyebutkan bahwa modul matematika efektif digunakan untuk meningkatkan motivasi belajar siswa.

Beberapa peneliti relevan yang terkait dengan analisis kebutuhan desain modul matematika berbasis santun berbahasa adalah yang pertama pengembangan modul matematika untuk siswa slow learner yang mendapatkan hasil efektif untuk meningkatkan kemampuan matematis siswa (Wanabuliandari
Purwaningrum, 2018). Kedua penelitian dari (Aziz et al., 2016) yang menganalisis proses pembelajaran matematika pada siswa slow lerner serta pemahaman guru terhadap karakteristik siswa slow learner. Ketiga (Maryati \& Priatna, 2017) terkait dengan integrasi santun dalam pembelajaran matematika agar pembelajaran matematika lebih bermakna. Keempat (Ristiyani; \& Ahsin, 2017) terkait pengembangan modul kesantunan berbahasa yang efektif meningkatkan pemahaman anak terhadap bahasa yang santun. Dari penelitian tersebut akan menjadi dasar dalam pengembangan desain modul matematika berbasis santun berbahasa. modul matematika berbasis santun berbahasa saat ini belum ada yang mengembangkan. Oleh karena itu peneliti fokus meneliti tentang analisis kebutuhan modul matematika berbasis santun berbahasa pada siswa slow learner serta mencoba merumuskan desain draf modul matematika berbasis santun berbahasa untuk siswa slow learner di sekolah dasar.

Bahasa yang santun diperlukan dalam keseharian agar generasi muda tidak lupa dengan kesantunan bangsa (Alfiati, 2015). Bahasa santun ini diperlukan agar guru memahami bagaimana berkomunikasi yang baik dengan siswa slow learner. Mengingat siswa slow learner berbeda dengan siswa biasa. (Wanabuliandari \& Ristiyani, 2019) menyebutkan bahwa melalui bahasa yang santun atau positif akan membantu guru untuk memahami karakteristik siswa. (Gilang et al., 2018) menyebutkan bahwa desain modul memberikan pengaruh terhadap aktivitas belajar siswa. Hal ini berarti bahwa dalam mengembangkan modul juga harus diperhatikan desain modulnya. Ini dilakukan agar siswa slow learner tertarik untuk membaca 
DOI: https://doi.org/10.24127/ajpm.v9i3.2889

dan memahami isi modul. Oleh karena itu guru dapat mengembangakan modul yang sesuai dengan karakteristik siswa agar siswa lebih tertarik dalam belajar matematika.

Sedangkan tujuan dari penelitian ini adalah (1) untuk menganalisis hasil studi lapangan terkait kebutuhan desain modul matematika berbasis santun berbahasa untuk siswa slow learner di sekolah dasar, (2) untuk menganalisis hasil temuan di lapangan dan hasil FGD terkait kebutuhan terkait kebutuhan desain modul matematika berbasis santun berbahasa untuk siswa slow learner di sekolah dasar, (3) merumuskan desain draf modul matematika berbasis santun berbahasa untuk siswa slow learner di sekolah dasar.

\section{METODE PENELITIAN}

Penelitian ini disusun dengan menggunakan pendekatan kualitatif. Pendekatan ini digunakan untuk dapat memperoleh informasi dan data secara mendalam terkait permasalahan yang diteliti. Metode penelitian yang digunakan yaitu deskriptif. Metode ini digunakan untuk menggambarkan desain pembuatan modul matematika berbasis santun berbahasa. Teknik pengambilan sampel dalam penelitian ini yaitu menggunakan teknik Purposive Sampling.

Modul ini dirancang dengan memperhatikan karakteristik siswa slow learner. Modul dirancang dengan menggunakan Ms. Office Word untuk isi modul, sedangkan Corel Draw dan Photoshop untuk membuat desain sampul dan tema modul.Tema modul yang digunakan menggunakan tema kearifan lokal yang ada di Indonesia. Rancangan penelitian terhadap desain modul terdiri dari beberapa tahap yaitu (1) studi pendahuluan, (2) analisis temuan, (3) desain kegiatan pembelajaran, (4) desain bahasa santun, (5) desain cerita budaya pada modul, (6) desain contoh soal dan latihan, (7) desain penilaian modul, dan (8) desain tema, halaman serta sampul modul.

Lokasi dalam penelitian ini berada di Universitas Muria Kudus dan SD 5 Bae Kudus. SD 4 Bae Kudus menjadi tempat untuk melaksanakan studi penedahuluan. Universitas Muria Kudus digunakan sebagai tempat untuk melaksanakan kegiatan perumusan analisisi temuan dan perumusan desain draf modul matematika berbasis santun berbahasa. Penelitian ini dilaksanakan pada bulan Mei - November 2019.

Subjek penelitian ini yaitu 1 guru dan 17 siswa slow learner di kelas IV SD 5 Bae yang telah dipilih berdasarkan hasil tes psikologi. Teknik pengumpulan data yang digunakan adalah teknik non tes. Teknik non tes digunakan dalam penelitian dengan tujuan untuk mengumpulkan data yang datanya bersifat kualitatif yaitu data hasil wawancara dengan guru dan siswa slow learner, hasil observasi, dan hasil dokumentasi.

Wawancara digunakan untuk memperoleh data terkait pembelajaran, media, serta kebutuhan pengembangan modul yang sesuai dengan kebutuhan siswa. bahan Untuk memperoleh data hasil wawancara dengan guru dan siswa slow learner langkahnya adalah (1) menentukan subjek yang akan diwawancarai yaitu guru dan siswa slow learner, (2) mempersiapkan bahan pertanyaan yang akan dijadikan bahan wawancara, (3) melaksanakan kegiatan wawancara, (4) mengkonfirmasi rangkuman hasil wawancara, (5) menuliskan hasil wawancara kedalam catatan lapangan, dan (6) mengidentifikasi tindak lanjut hasil wawancara. 
DOI: https://doi.org/10.24127/ajpm.v9i3.2889

Observasi yang dilakukan peneliti adalah untuk mendapatkan data terkait dengan bahan ajar yang disediakan oleh sekolah. Hasil observasi ini akan dijadikan rujukan dalam pembuatan desain modul matematika berbasis santun berbahasa. Langkah observasi yang dilakukan adalah (1) menentukan bahan yang akan diobservasi, (2) melaksanakan kegiatan observasi, (3) menuliskan hasil observasi kedalam catatan lapangan, dan (4) mengidentifikasi tindak lanjut hasil observasi. Dokumentasi digunakan untuk mencari data terkait dengan desain pengembangan modul matematika berbasis kesantunan berbahasa yang berupa catatan lapangan, jurnal, dan buku. Catatan lapangan peneliti peroleh berdasarkan hasil wawancara dan observasi yang sudah dilakukan. Jurnal dan buku dijadikan kajian dalam pengembangan desain modul matematika berbasis kesantunan berbahasa.

Teknik analisis data menggunakan model Miles dan Huberman. Pada model ini terdapat tiga kegiatan yaitu reduksi data, penyajian data, dan melakukan penarikan kesimpulan. Tahapan yang pertama adalah reduksi yaitu memilih data yang sesuai dengan kebutuhan penelitian. Reduksi dimulai sejak pengumpulan data. Prosesnya dimulai dari meringkas, mengkode, dan memilih kesesuaian dengan penelitian kemudian membuang data yang tidak relevan, setelah itu data diverifikasi. Selanjutnya adalah tahap penyajian data. Pada tahap ini data yang sudah direduksi kemudian disajikan. Penyajian data kualitatif disajikan dalam penelitian ini dalam bentuk teks naratif agar dapat menggabungkan informasi yang tersusun dalam bentuk yang terpadu serta mudah untuk dipahami. Setelah tahap penyajian data dilanjutkan dengan tahap penarikan kesimpulan. Pada tahap ini peneliti melakukan akan mengungkapkan makna dari data yang sudah dikumpulkan. Penarikan kesimpulan dilakukan dengan melihat kembali hasil reuksi datamaupun display sehingga kesimpulan yang diambil sesuai. Kesimpulan ini akan menjawab rumusan masalah yang dirumuskan sejak awal, tapi bisa juga tidak sesuai. Hal ini karena rumusan masalah bersifat sementara dan dapat berkembang sesuai dengan kondisi di lapangan. Penarikan kesimpulan dalam penelitian ini dideskripsikan berdasarkan hasil penelitian di lapangan.

\section{HASIL DAN PEMBAHASAN}

Analisis Hasil Studi Lapangan

Studi Pendahuluan dilaksanakan untuk mengetahui kondisi di lapangan. Kondisi di lapangan ini dapat menjadi temuan yang nanti akan digunakan untuk mencari solusi dari temuan tersebut. Solusi ini nantinya dapat memperbaiki permasalahan yang terjadi. Berdasarkan hasil studi lapangan di temukan bahwa bahan ajar yang digunakan adalah buku dari paket dari pemerintah, siswa juga menggunakan LKS dari penerbit, guru belum mengembangkan bahan ajar sendiri, serta bahan ajar yang digunakan oleh siswa belum memuat materi yang dikaitkan dengan kondisi lingkungan sekitar. (Ramadhani \& Amudi, 2020) menyebutkan bahwa masih banyak buku teks yang menyajikan materi secara tidak terstuktur. (Melisa, 2015) menyebutkan bahwa buku teks kurang memotivasi siswa untuk belajar.

Sedangkan hasil wawancara dengan guru menunjukkan bahan ajar yang selama ini digunakan belum menyajikan materi pembelajaran sesuai dengan kondisi lingkungan yang ada di 
daerah, dan guru kesulitan saat mencoba mengkaitkan materi dengan contoh yang ada di lingkungan sekitar. Selain itu, berdasarkan hasil wawancara guru belum memahami karakteristik siswa slow learner, belum memahami ciri siswa slow learner, dan cara menangani siswa slow learner.

Berdasarkan hasil wawancara yang telah dilakukan pada guru, didapat informasi bahwa guru selama ini ketika menghadapi siswa slow learner belum menggunakan pemilihan bahasa yang santun. Beberapa data menunjukkan jika guru lebih banyak menggunakan kalimat negatif yang mengarah pada verbal bullying. Contohnya, seperti kalimat "Awas ya kalau tidak bisa menjawab, nanti saya hukum berdiri di depan kelas." Kalimat serupa juga diucapkan oleh guru seperti "yang tidak mengerjakan PR nanti mengerjakan di luar." Hasil wawancara dengan siswa menunjukkan bahwa siswa mengharapkan bahan ajar menarik disertai banyak gambar, ada komiknya dan berwarna. Siswa juga sependapat bahwa matematika sulit dikarenakan kesulitan dalam berhitung maupun memahami masalah. (Siniguian, 2017) menyebutkan bahwa siswa mengalami kesulitan matematika dikarenakan ketidakmampuan menerjemahkan masalah kedalam bentuk matematika sehingga tidak dapat digunakan dengan baik.

Menurut siswa guru jarang menggunakan media pembelajaran dan hanya menggunakan buku yang tersedia. (Wanabuliandari, 2015) menyebutkan bahwa melalui pemanfaatan media pembelajaran dapat mendukung siswa dalam belajar. Siswa juga menyebutkan bahwa pernah mengalami verbal bullying ketika di sekolah. Berdasarkan hasil wawancara dengan siswa, diperoleh informasi bahwa ketika pembelajaran matematika dan siswa tidak bisa mengerjakan, maka guru mengucapkan "hush meneng, ayo dikerjakan." Kalimat lain juga pernah didengarkan siswa saat tidak mengerjakan PR "Awas ya kalau tidak dikerjakan." Hasil wawancara tentang sumber belajar/ bahan ajar dengan 17 siswa didapatkan hasil pada Tabel 1.

Tabel 1. Hasil Wawancara Siswa

\begin{tabular}{|c|c|c|}
\hline No & Pertanyaan & $\begin{array}{c}\text { Hasil } \\
(\%)\end{array}$ \\
\hline 1 & $\begin{array}{l}\text { Apakah kamu menyukai } \\
\text { sumber belajar yang } \\
\text { banyak gambarnya? }\end{array}$ & 100 \\
\hline 2 & $\begin{array}{l}\text { Apakah kamu menyukai } \\
\text { sumber belajar yang ada } \\
\text { komiknya? }\end{array}$ & 100 \\
\hline 3 & $\begin{array}{l}\text { Apakah kamu menyukai } \\
\text { sumber belajar yang } \\
\text { berwarna-warni? }\end{array}$ & 82,4 \\
\hline 4 & $\begin{array}{l}\text { Apakah kamu menyukai } \\
\text { sumber belajar yang ada } \\
\text { kegiatan yang menarik? }\end{array}$ & 76,5 \\
\hline
\end{tabular}

Hasil wawancara menunjukkan bahwa semua siswa suka buku yang banyak gambar dan memuat komik. Kemudian sebanyak $82,4 \%$ responden menjawab menyukai buku yang berwarna warni. Sedangkan sebanyak $76,5 \%$ menyukai kegiatan yang menarik. (Pujiati et al., 2018) menyebutkan bahwa melalui pembelajaran yang menarik dapat memotivasi belajar siswa. (Nikmah et al., 2019) juga menyebutkan bahwa pembelajaran harus dibuat semenarik mungkin agar siswa lebih tertarik.

\section{Analisis Temuan dan Hasil Focus Group Discussion (FGD)}

Penyusunan desain draf modul matematika berbasis santun berbahasa berdasarkan temuan pada hasil studi pendahuluan di lapangan. Hasil studi 
DOI: https://doi.org/10.24127/ajpm.v9i3.2889

pendahuluan kemudian dibahas dalam focus group discussion (FGD) untuk memperoleh masukan dalam penyusunan desain draf modul matematika berbasis santun berbahasa. Hasil FGD didapatkan adalah sebagai berikut.

1. Modul matematika berbasis santun berbahasa menggunakan kurikulum 2013.

2. Kegiatan pembelajarannya dibuat menarik, dan ada kegiatan proyek.

3. Dalam modul matematika berbasis santun berbahasa memasukkan bahasa santun yang ditujukan untuk siswa slow learner.

4. Desain materi contoh soal, latihan soal, serta penyelesaiannya dibuat runtut, detail, dan jelas.

5. Desain tema dalam modul matematika berbasis santun berbahasa dikaitkan dengan kebudayaan di Indonesia.

6. Desain penilaian memperhatikan karakteristik siswa slow learner.

7. Desain halaman, serta sampul modul matematika berbasis santun berbahasa dikaitkan dengan kebudayaan di Indonesia.

Hasil FGD ini nantinya digunakan untuk merancang modul matematika berbasis santun berbahasa. Diharapkan melalui hasil FGD ini dapat disusun rancangan modul matematika berbasis santun berbahasa yang dapat digunakan guru untuk membantu siswa slow learner. Sehingga tindakan verbal bullying tidak lagi terjadi. Dengan demikian siswa Slow learner menjadi lebih termotivasi dalam belajar matematika.

\section{Desain Draft Modul matematika berbasis santun berbahasa}

Hasil studi pendahuluan dan analisis temuan yang telah digunakan sebagai acuan dan dasar dalam pengembangan desain modul matematika berbasis santun berbahasa. (Febriasari \& Wijayanti, 2018) menyebutkan bahwa Santun berbahasa ini penting dikembangkan mengingat semakin berkembangnya budaya maka semakin ditinggalkannya ke santunan ini. Oleh karena itu dalam mengembangkan modul matematika perlu dilengkapi dengan penggunaan bahasa yang santun.

Produk yang dihasilkan dalam bentuk modul memiliki karakteristik yang berbeda dengan modul lainnya. Modul matematika berbasis santun berbahasa menyajikan materi pembelajaran matematika secara runtut dan jelas serta memperhatikan kesantunan berbahasa dalam setiap kalimatnya baik kalimat perintah, penjelasan maupun soal-soalnya. (Novitasari et al., 2018) menyebutkan bahwa siswa slow learner memiliki masalah dalam memahami, mentransformasi, memproses, dan melakukan pengkodean. Tentu saja ini menjadi pertimbangan dalam mengembangkan materi matematika yang disajikan secara runtut.

Modul matematika berbasis santun berbahasa dirancang memiliki 3 bagian pokok yaitu bagian pendahuluan, isi, dan penutup. Bagian pendahuluan meliputi halaman muka, kata pengantar, petunjuk penggunaan modul, daftar isi, peta konsep, dan kompetensi pembelajaran. Bagian isi merupakan bagian yang paling penting dalam modul matematika berbasis santun berbahasa. Bagian isi terdiri dari beberapa kegiatan belajar yang menuntut siswa slow learner mencapai kompetensi di setiap kegiatan belajar sebelum melanjutkan pada kegiatan belajar berikutnya. Desain pada masingmasing kegiatan belajar disusun dengan menggunakan akronim unik sehingga 
DOI: https://doi.org/10.24127/ajpm.v9i3.2889

menarik dan mudah diingat oleh siswa Slow learner. Isi dari modul matematika berbasis santun berbahasa yang disusun dapat dilihat pada Gambar 1. Pada Gambar 1 ini merupakan cermin isi modul

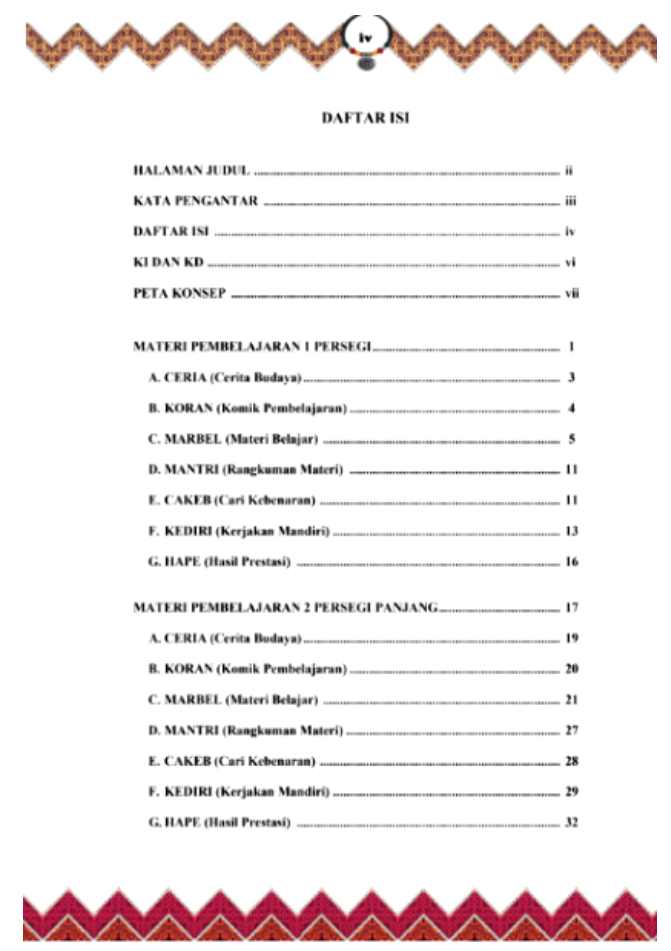

Gambar 1. Daftar isi modul matematika berbasis santun berbahasa.

Draf modul Matematika Berbasis Santun Berbahasa memiliki kekhasan. Bahasa yang digunakan menggunakan teori kesantunan berbahasa sehingga siswa Slow learner merasa nyaman dan tertarik. Modul ini juga memiliki sub bagian atau rubrik yang terdiri dari Ceria (Cerita Budaya), Koran (Komik Pelajaran), Marbel (Mari Belajar), Mantri (Rangkuman Materi), Cakeb (Cari Kebenaran), Kediri (Kerjakan Mandiri), dan Hape (Hasil Prestasi).

Adapun kekhasan modul matematika berbasis santun berbahasa ini terletak pada kalimat perintah. Pada kalimat perintah di modul pada umumnya menggunakan kalimat perintah langsung seperti "Kerjakan soal berikut!", akan tetapi pada modul ini menggunakan kalimat ajakan "Ayo anak-anak yang rajin, kita kerjakan soal berikut". (Astuti Th., 2012) Dengan menggunakan buku yang santun akan meningkatkan kesantunan dalam berbicara dengan orang lain. Senada dengan (Zamzani et al., 2011) yang menyebutkan bahwa kesantunan berbahasa dapat membimbing penuturnya kearah yang positif sekaligus memperkuat jati dirinya.

Pertama adalah akronim Ceria yang berarti Cerita Budaya. Pada bagian ini siswa slow learner akan diberikan wawasan kebudayaan yang berkaitan dengan materi. Salah satu konten dari cerita budaya yang ada di dalam modul dapat dilihat pada Gambar 2.

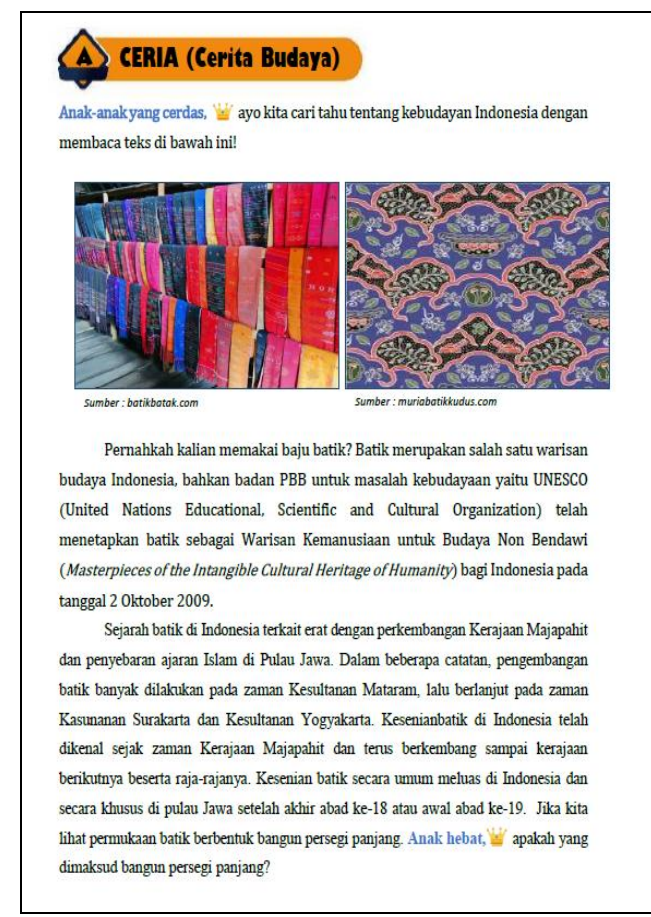

Gambar 2. Tampilan pada rubrik Ceria (Cerita Budaya) pada materi 1 persegi.

Pada rubrik Ceria materi 1 Persegi panjang, siswa diberi wacana tentang persegi panjang dalam 
DOI: https://doi.org/10.24127/ajpm.v9i3.2889

kehidupan nyata. Persegi panjang dihubungkan dengan bentuk kain batik.

Kedua adalah Koran atau Komik Pembelajaran (Gambar 3). Pada rubrik ini siswa diberi sajian komik yang menarik. (Arini et al., 2017) menyebutkan bahwa dengan menggunakan media komik minat belajar siswa Slow learner meingkat. Rubrik ini juga menjadi kelebihan dalam modul ini mengingat dalam buku mata pelajaran Matematika jarang ada sajian komik. Tujuan rubrik ini mengajak siswa untuk mengenali materi dengan bahasa yang santun. Akfiati (2015) menyebutkan kesantunan berbahasa merupakan aspek dari segi bahasa yang dapat meningkatkan kecerdasan emosional pemakainya karena terdapat komunikasi serta komitmen untuk menjaga keharmonisan suatu hubungan.

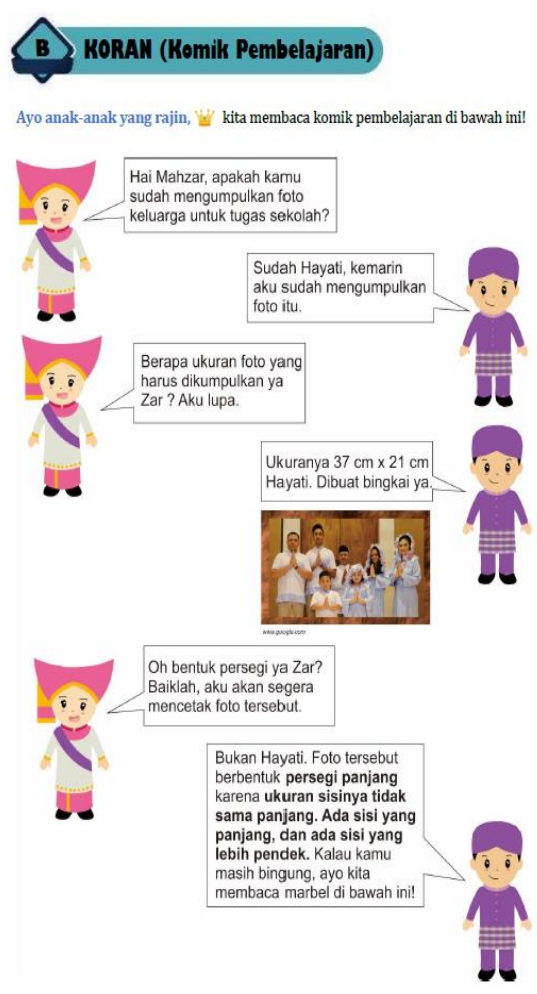

Gambar 3. Tampilan pada rubrik Koran.

Ketiga, Marbel artinya Mari Belajar. Pada rubrik ini siswa diberi pengetahuan tentang materi dengan visual yang menyenangkan. Bahasa yang digunakan sangat mudah dipahami. Tampilan Mari belajar dapat dilihat pada Gambar 4 dan Gambar 5.

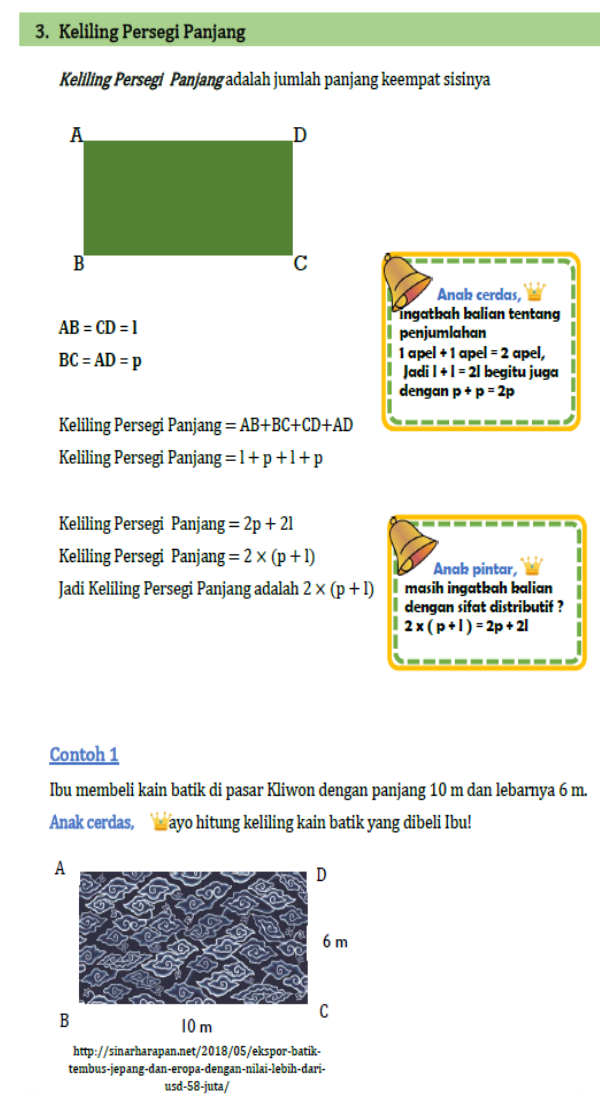

Gambar 4. Tampilan pada rubrik Marbel dari segi penjelasan materi.

Dari Gambar 4 menunjukkan bahwa siswa selalu diingatkan kembali tentang materi sebelumnya agar siswa ingat pembahasan sebelumnya. Hal ini dilakukan mengingat siswa slow learner harus dijelaskan secara runtut dan berulang-ulang. Siswa slow learner cenderung mengalami kecemasan dan cepat menyerah. Oleh karena itu pada segi penjelasan materi harus dijelaskan serinci mungkin agar siswa Slow learner tidak menyerah dan tetap bersemangat untuk membaca materi yang diberikan. Sedangkan untuk Gambar 5 menunjukkan Tampilan Mari 
DOI: https://doi.org/10.24127/ajpm.v9i3.2889

belajar dari segi pemberian contoh dan langkah pengerjaan.

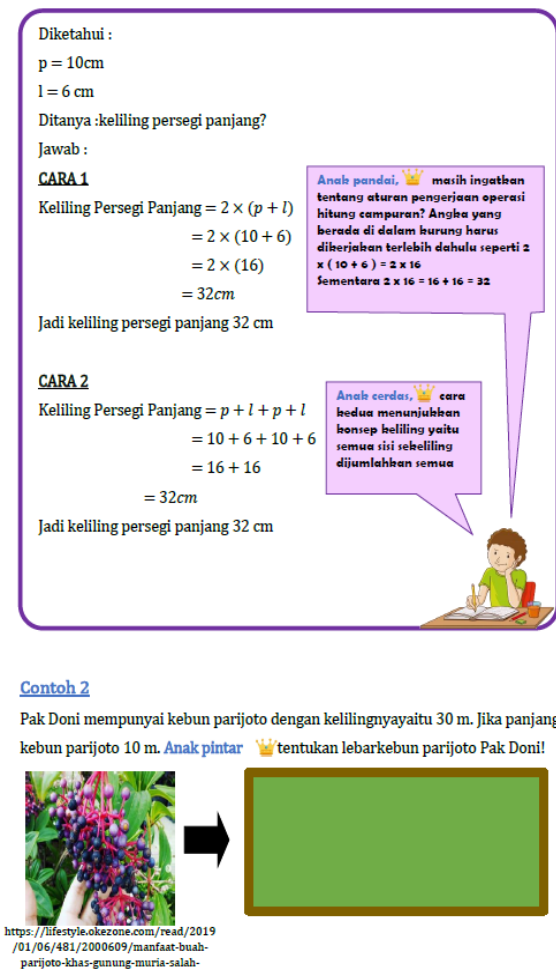

Gambar 5. Tampilan pada rubrik Marbel dari segi contoh soal.

Pada rubrik marbel materi disampaikan dengan ringkas. Hal ini karena tingkat pemahaman siswa Slow learner berbeda dengan siswa biasa. Contoh soal dan penyelesaian dibuat sedetail mungkin sehingga siswa Slow learner dapat lebih paham. (Pruett, 2010) menjelaskan bahwa sebenarnya siswa Slow learner dapat belajar ditingkat yang lebih tinggi akan tetapi tingkat pemahamannya lebih lambat daripada siswa biasa. Lalu dilanjutkan dengan Mantri (Rangkuman Materi). Pada rubrik ini siswa diberi sajian rangkuman materi. Tujuan rubrik ini untuk mempermudah siswa dalam memahami dan merangkum materi. Tampilan dari rubrik Mantri dapat dilihat pada Gambar 6.

\section{MANTRI(Rangkuman Materi)}

Persegi panjang merupakan bangun datar yang mempunyai dua pasang sisi yang berhadapan sama panjang dan empat sudut sama besar.

Sifat-sifat persegi panjang yaitu punya 2 pasang sisi yang berhadapan sama panjang, punya 4 sudut sama besar (sudut siku-siku), punya 2 diagonal saling berpotongan. dan dapat menempati bingkainya $4 \mathrm{cara}$.

Benda yang berbentuk persegi panjang yaitu buku, pintu, tempat pensil. lukisan, meja, nampan dan lain-lain.

Rumus keliling persegi panjang yaitu $2(p+1)$

Rumus luas persegi panjang yaitu $\mathrm{p} \times 1$

Gambar 6. Tampilan pada rubrik Mantri

Selanjutnya adalah Cakeb (Cari Kebenaran) pada Gambar 7. Pada rubrik ini siswa diajak mencari kebenaran dengan kegiatan yang menyenangkan. Kegiatan yang dimaksud seperti eksperimen. Dalam cari kebenaran menggunakan bahasa yang santun sehingga membuat anak-anak merasa senang dan tidak takut saat mengerjakan. Sebaiknya guru dapat mengulang secara lisan langkah kegiatan eksperimen pada rubrik ini agar siswa slow learner merasa nyaman dengan guru.

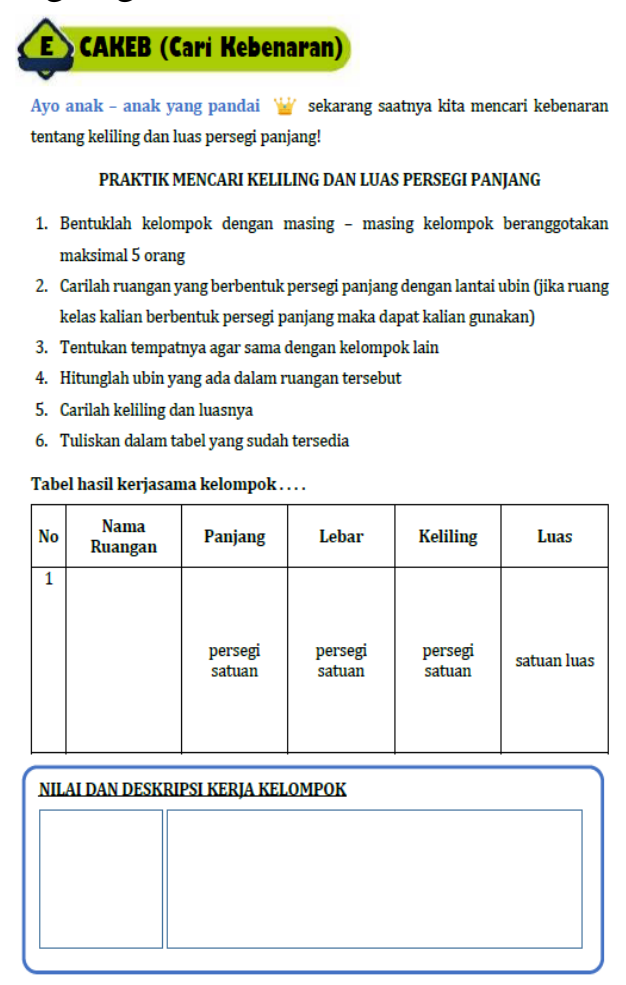

Gambar 7. Tampilan pada rubrik Cakeb 
DOI: https://doi.org/10.24127/ajpm.v9i3.2889

Dilanjut dengan Kediri (Kerja Mandiri) pada Gambar 8. Pada rubrik ini siswa akan diminta untuk mengerjakan soal secara mandiri. Hal ini dimaksudkan agar guru mengetahui mana siswa yang sudah paham atau belum. Pada kerja mandiri ini penyelesaian soal dibuat sedetail mungkin. Mengingat siswa Slow learner yang terlalu berbeda jauh sehingga memerlukan latihan soal yang hampir mirip. Dalam penyelesian soal juga masih dituntun agar siswa slow learner mengingat cara menyelesaikannya. Untuk soal nomor 5 diharapkan siswa slow learner bisa menjawab tanpa harus dituntun oleh guru.

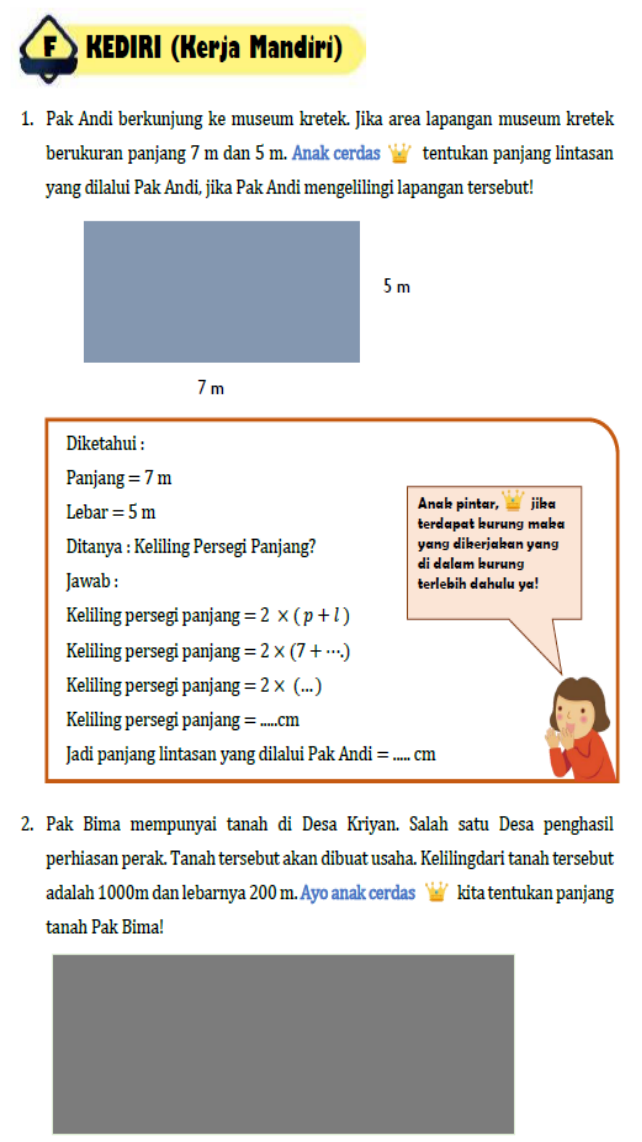

Gambar 8. Tampilan pada rubrik Kediri

Pada kegiatan mandiri ini siswa slow learner diberikan soal yang hampir mirip dengan contoh soal. Hal ini karena siswa slow learner tidak dapat langsung menerapkan materi yang didapat pada situasi atau permasalahan Dilanjutkan dengan Hape (Hasil Prestasi). Pada rubrik ini siswa diminta mewarnai gambar bintang pada nilai yang mereka dapatkan. Gambar 9 menunjukkan tampilan dari hasil prestasi

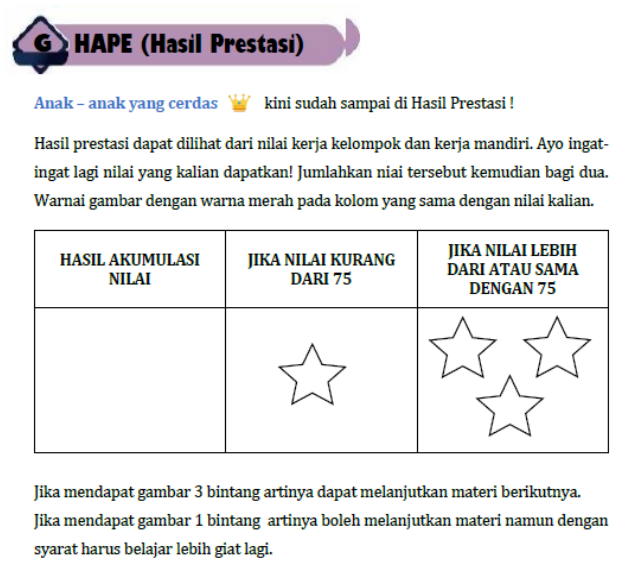

Gambar 9. Tampilan rubrik Hape

Rubrik yang tersedia dalam modul Matematika berbasis Santun Berbahasa ini telah disesuaikan dengan kebutuhan siswa slow learner. (Frisby, 2013) menyebutkan bahwa siswa slow learner cederung mudah kehilangan minat karena lebih berusaha dan lebih lambat dari siswa biasa. Sehingga dalam pengembangan modul matematika berbasis santun berbahasa ini dapat membuat siswa slow learner tertarik dan paham dengan materi yang diberikan. Manfaat yang didapatkan melalui penelitian adalah guru mampu memiliki gambaran dalam mengembangkan modul matematika berbasis santun berbahasa yang ditujukan siswa slow learner sehingga nantinya dapat mengembangkan modul sendiri berdasarkan karateristik siswa Slow learner. Dengan demikian, harapannya siswa merasa nyaman dan senang ketika belajar matematika. Selain itu diharapkan melalui modul 
DOI: https://doi.org/10.24127/ajpm.v9i3.2889

matematika berbasis santun berbahasa dapat mengurangi bentuk verbal bullying yang dilakukan oleh guru.

Berdasarkan hasil studi pendahuluan dan analisis kebutuhan menunjukan bahwa perlu dikembangkan modul matematika yang mengarah pada kesantunan berbahasa. Penelitian dari (Wanabuliandari \& Purwaningrum, 2018) menjelaskan bahwa modul matematika untuk siswa slow learner dapat meningkatkan kemampuan pemecahan masalah. Penelitian ini tentu saja sejalan dengan temuan dilapangan terkait kebutuhan pengembangan modul untuk siswa slow learner. Selain itu, penelitian ini menjadi dasar dalam pengembangan modul matematika untuk siswa slow learner.

Ada juga penelitian dari (Maryati \& Priatna, 2017) terkait dengan integrasi nilai santun dalam pembelajaran matematika yang memang diperlukan. Hal ini tentu saja sejalan dengan hasil temuan dilapangan bahwa untuk mmengurangi tindak verbal bullying pada siswa slow learner diperlukan sumber belajar yang dapat mengintegrasi nilai kesantunan. Hal ini diperlukan agar siswa slow learner tidak merasa terintimidasi oleh guru. Bagi guru tentu saja dapat menjadi pedoman dalam berbahasa yang baik terutama ketika bertemu dengan siswa slow learner.

(Aziz et al., 2016) dalam penelitiananya melaksanakan kegiatan analisis proses pembelajaran matematika pada siswa slow lerner serta pemahaman guru terhadap karakteristik siswa slow learner. Dalam penelitian ini mengemukakan pentingnya memahami karakteristik siswa slow learner. Penelitian ini sejalan dengan temuan bahwa masih banyak guru yang belum memahami karakteristik siswa slow learner sehingga kecenderungan untuk melakukan verbal bullying tanpa sengaja bisa terjadi, penelitian ini juga akan dijadikan pendukung dalam pengembangan modul matematika berbasis kesantunan berbahasa.

(Ristiyani; \& Ahsin, 2017) terkait pengembangan modul kesantunan berbahasa yang efektif meningkatkan pemahaman anak terhadap bahasa yang santun. Dari penelitian tersebut akan menjadi dasar dalam pengembangan modul matematika berbasis santun berbahasa. Selain itu, saat ini belum ada yang mengembangan modul matematika berbasis kesantunan berbahasa yang ditujukan untuk siswa slow learner. Ada penelitian terkait pengembangan modul matematika tapi tidak mengarah kekesantunan berbahasa. Ada juga yang mengembangkan modul kesantuna tapi bukan untuk mata pelajaran matematika. Ada pula kajian terkait siswa slow learner dan kesantunan tapi tidak membahas tentang pengembangan modul matematika berbasis kesantunan berbahasa. Dengan demikian, jelas bahwa memang perlu dikembangkan modul matematika berbasis kesantunan berbahasa untuk membantu siswa slow learner memahami materi. Selain itu juga membantu guru dan siswa dari pengaruh verbal bullying.

\section{KESIMPULAN DAN SARAN}

Kesimpulan dari hasil penelitian ini adalah (1) berdasarkan hasil studi lapangan modul matematika berbasis santun berbahasa membahas materi pembelajaran matematika secara koheren dan jelas perlu untuk dikembangkan dengan memperhatikan kesantunan dalam setiap kalimat baik kalimat perintah, penjelasan dan pertanyaan; (2) berdasarkan temuan dan FGD perlu dirancang modul yang 
menggunakan kurikulum 2013, ada kegiatan proyek yang menarik, memasukkan bahasa yang santu, isinya runtut dan detail, tema tentang kebudayaan, memperhatikan karakter siswa slow learner, desain halaman dan sambul berkaitan dengan budaya; dan (3) Desain draft modul matematika berbasis santun berbahasa menyediakan 3 bagian dasar dari pengantar, konten, dan penutup, serta desain setiap kegiatan pembelajaran disusun menggunakan akronim yang unik sehingga menarik dan mudah diakses oleh siswa yang lambat seperti Ceria (Cerita Budaya ), Koran (Komik Pelajaran), Marbel (Mari Belajar), Mantri (Rangkuman Materi), Cakeb (Cari Kebenaran), Kediri (Kerjakan Mandiri), dan Hape (Hasil Prestasi).

Saran yang dapat disampaikan adalah (1) dalam mengembangkan modul matematika berbasis santun berbahasa perhatikan karakteristik siswa slow learner, (2) pilih bahasa santun yang dapat memotivasi siswa slow learner, dan (3) Pengembangan modul matematika berbasis santun berbahasa memperhatikan runtutan materi, contoh soal yang sesuai dengan pemahaman siswa slow learner, serta latihan soal yang disesuaikan dengan kemampuan siswa slow learner.

\section{DAFTAR PUSTAKA}

Alfiati, A. (2015). Santun Berbahasa Indonesia. An-Nuha: Jurnal Kajian Islam, Pendidikan, Budaya Dan Sosial, 2(1), 17-34.

Arini, F. D., Choiri, A. S., \& Sunardi. (2017). The Use of Comic As a Learning Aid To Improve Learning Interest of Slow Learner Student. European Journal of Special Education Research, 2(1), 71-78. https://doi.org/10.5281/zenodo.221 004
Astuti Th., P. K. (2012). Perbedaan Tingkat Kesantunan Berbahasa Aspek Berbicara Dan Menulis Hasil Belajar Menggunakan Buku Ajar Santun Berbahasa Indonesia Dan Bahasa Indonesia (Bse) Pada Siswa Kelas VII SMP Dengan Model Pertemuan Kelas. Seloka Jurnal Pendidikan Bahasa Dan Sastra Indonesia, 1(1), 69-78.

Aziz, A. N., Sugiman, S., \& Prabowo, A. (2016). Analisis Proses Pembelajaran Matematika pada Anak Berkebutuhan Khusus (ABK) Slow Learner di Kelas Inklusif. Kreano, Jurnal Matematika Kreatif-Inovatif, 6(2), 111-120.

https://doi.org/10.15294/kreano.v6i 2.4168

Borah, R. R. (2013). Slow Learners: Role of Teachers and Guardians in Honing their Hidden Skills. International Journal of Educational Planning \& Administration, 3(2), 2249-3093. http://www.ripublication.com/ijepa .htm

Ekayanti, A. (2017). Pengembangan Modul Irisan Kerucut Berbantuan Geogebra. AKSIOMA: Jurnal Program Studi Pendidikan Matematika, 6(3), 308-314. https://doi.org/10.24127/ajpm.v6i3. 1151

Febriasari, D., \& Wijayanti, W. (2018). Kesantunan Berbahasa Dalam Proses Pembelajaran Di Sekolah Dasar. KREDO : Jurnal Ilmiah Bahasa Dan Sastra, 2(1), 140-156. https://doi.org/10.24176/kredo.v2i 1.2557 
Frisby, C. L. (2013). Meeting the Psychoeducational Needs of Minority Students: EvidenceBased Guidelines for School Psychologists and other School Personnel. In Meeting the Psychoeducational Needs of Minority Students: Evidence-Based Guidelines for School Psychologists and other School Personnel. John Wiley \& Sons, Inc.

https://doi.org/10.1002/978111809 2620

Gilang, L., Sihombing, R. M., \& Sari, N. (2018). Pengaruh Konteks pada Ilustrasi Buku Pendidikan Karakter terhadap Perilaku Disiplin Anak Usia Dini. Scholaria: Jurnal Pendidikan Dan Kebudayaan, 8(1), 41-50. https://doi.org/10.24246/j.js.2018.v 8.i1.p41-50

Kaltiala, H., \& Riittakerttu, F. (2011). Correlation between bullying and clinical depression in adolescent patients. Adolescent Health, Medicine and Therapeutics, 2, 3744. https://doi.org/10.2147/ahmt.s1155 4

Maryati, I., \& Priatna, N. (2017). Integrasi Nilai-Nilai Karakter Matematika Melalui Pembelajaran Kontekstual. Mosharafa: Jurnal Pendidikan Matematika, 6(3), 333-344.

https://doi.org/10.31980/mosharafa .v6i3.322

Melisa. (2015). Pengembangan Modul Berbasis Penemuan Terbimbing Yang Valid Pada Perkuliahan Kalkulus Peubah Banyak I. Lemma, I(2), 21-27.
Nikmah, A. A., Wanabuliandari, S., \& Bintoro, H. S. (2019). Peningkatan Pemahaman Konsep Matematis Melalui Model STAD Berbantu Media Puzzle Pecahan Siswa Kelas Iv Sd N 1 Buwaran. Seminar Nasional Pendidikan Matematika (SNAPMAT), 58-65.

Novitasari, N., Lukito, A., \& Ekawati, R. (2018). Slow Learner Errors Analysis in Solving Fractions Problems in Inclusive Junior High School Class. Journal of Physics: Conference Series, 947(1), 1-6. https://doi.org/10.1088/17426596/947/1/012035

Pruett, K. E. (2010). Differences in academic achievement and academic self-concept based on intellectual ability, grade retention, and special education status. Western Carolina University.

Pujiati, P., Kanzunnudin, M., \& Wanabuliandari, S. (2018). Analisis Pemahaman Konsep Matematis Siswa Kelas IV SDN 3 Gemulung Pada Materi Pecahan. ANARGYA: Jurnal Ilmiah Pendidikan Matematika, 1(1), 3741.

https://doi.org/10.24176/anargya.v $1 \mathrm{i} 1.2278$

Putri, I. A. P. G., Koyan, W., \& Candiasa, $\quad$ M. (2013). Pengembangan Tes Matematika Berbasis Sk/kd dengan Teknik Concurent pada Siswa Kelas VI di SD Negeri Se Kecamatan Gianyar. E-Journal Program Pascasarjana Universitas Pendidikan Ganesha Program Studi Penelitian Dan Evaluasi Pendidikan, 3, 1-14. 
DOI: https://doi.org/10.24127/ajpm.v9i3.2889

Ramadhani, R., \& Amudi, A. (2020). Efektifitas Penggunaan Modul Matematika Dasar Pada Materi Bilangan Terhadap Hasil Belajar. AKSIOMA: Jurnal Program Studi Pendidikan Matematika, 9(1), 64. https://doi.org/10.24127/ajpm.v9i1. 2443

Ristiyani;, \& Ahsin, M. N. (2017). VALIDITAS BUKU SANTUN BERBAHASA UNTUK INTERAKSI PENGASUHAN BERBAHASA ANAK JALANAN DI RUMAH SINGGAH. Transformatika, 1(2), 246-261.

Setyawan, D. (2017). KPAI : 10 Persen Kekerasan Anak Dilakukan Oleh Guru, KPPPA Sulsel Canangkan SRA.

http://www.kpai.go.id/berita/kpai10-persen-kekerasan-anakdilakukan-oleh-guru-kpppa-sulselcanangkan-sra

Shetgiri, R. (2013). Bullying and victimization among children. Advances in Pediatrics, 60(1), 3351. https://doi.org/10.1016/j.yapd.2013 .04 .004

Siniguian, M. T. (2017). Students difficulty in solving mathematical problems. International Journal of Advanced Research in Engineering and Applied Sciences, 6(2), 1-12.

Sipayung, T. N., \& Simanjuntak, S. D. (2017). Efektivitas Pembelajaran Kooperatif Dengan Menggunakan Modul. AKSIOMA: Jurnal Program Studi Pendidikan Matematika, 6(3), 393-398.

Syahroni, M. W., Dewi, N. R., \& Kasmui. (2016). The Effect Of Using digimon (Science Digital
Module) with Scientific Approach At The Visualization of Students Independence And Learning Result. Jurnal Pendidikan IPA Indonesia, 5(1), 116-122. https://media.neliti.com/media/pub lications/121533-EN-the-effect-ofusing-digimon-science-digi.pdf

Waliyanti, E., Kamilah, F., \& Fitriansyah, R. R. (2018). Fenomena Perilaku Bullying pada Remaja di Yogyakarta. Jurnal Ilmiah Keperawatan Indonesia [JIKI], 2(1), 50-64. https://doi.org/10.31000/jiki.v2i1.8 31

Wanabuliandari, S. (2015). Keefektifan Model Pembelajaran Kooperatif Teams Assisted Individualization Dengan Macromedia Authorware Materi Segi Empat Kelas VII SMPN 3 Kudus. Refleksi Edukatika: Jurnal Ilmiah Kependidikan, 5(2), 1-12. https://doi.org/10.24176/re.v5i2.59 0

Wanabuliandari, S., \& Purwaningrum, J. P. (2018). Pembelajaran Matematika Berbasis Kearifan lokal Gusjigang Kudus Pada Siswa Slow learner. Eduma: Mathematics Education Learning and Teaching, 7(1), 63-70. https://doi.org/10.24235/eduma.v7i 1.2724

Wanabuliandari, S., \& Ristiyani, R. (2019). Program Hypnomathematics melalui KataKata Positif untuk Guru SD 4 Bae Kudus. Jurnal Pengabdian Pada Masyarakat, 4(3), 249-254. https://doi.org/10.30653/002.20194 3.150 
DOI: https://doi.org/10.24127/ajpm.v9i3.2889

Zamzani, Musfiroh, T., Maslakhah, S., Listyorini, A., \& Rahayu, Y. E. (2011). Pengembangan Alat Ukur Kesantunan Bahasa Indonesia Dalam Interaksi Sosial Bersemuka. LITERA, 10(1), 35-50. https://doi.org/10.21831/ltr.v10i1.1 171 